\title{
LA ACCIÓN DE INCONSTITUCIONALIDAD Y LOS TRATADOS INTERNACIONALES EN LA CONSTITUCIÓN POLÍTICA DE LOS ESTADOS UNIDOS MEXICANOS
}

\section{THE ACTION OF UNCONSTITUTIONALITY AND INTERNATIONAL TREATIES IN THE POLITICAL CONSTITUTION OF THE UNITED MEXICAN STATES}

\author{
Eduardo Alberto Herrera Montes ${ }^{1}$ \\ Alberto Herrera Pérez ${ }^{2}$
}

\section{RESUMEN}

No existen actualmente en el orden jurídico mexicano criterios o pautas específicas sobre los elementos que deben contener las sentencias dictadas en la acción de inconstitucionalidad declarativas de una contradicción entre un tratado internacional y el texto de la Constitución Política de los Estados Unidos Mexicanos. Igualmente es inexistente el procedimiento para su ejecución. El objetivo del presente ensayo es aportar elementos jurídico-legales que coadyuven en la elaboración de una normatividad reguladora del contenido, efectos y acciones posteriores de estas resoluciones judiciales cuyo dictado corresponde a la Suprema Corte de Justicia de la Nación de México. Partiremos para este efecto del análisis de diversos ordenamientos legales y criterios del Poder Judicial de la Federación, los casos de Tribunales Constitucionales de otros países, así como de opiniones de organismos internacionales y doctrinales.

Palabras clave: Acción de inconstitucionalidad, Constitución Mexicana, tratados internacionales, normas generales, supremacía constitucional, contradicción.

\begin{abstract}
Currently, in the Mexican legal order, there are no specific rules on the elements that must be contained in the sentences issued in the unconstitutionality action that declares a contradiction between an international treaty and the text of the Political Constitution of the United Mexican States. Equally, the procedure for its execution is non-existent. The objective of this essay is to provide legal elements for the elaboration of a regulation that regulates the content, effects and subsequent actions of these judicial resolutions issued by the Supreme Court of Justice of the Nation

\footnotetext{
${ }^{1}$ Licenciado en Derecho por la Universidad Nacional Autónoma de México. Especialista en Derecho Penal por la Universidad Panamericana. Especialista en Derecho Constitucional por la Universidad Nacional Autónoma de México. Maestro en Derecho por la Universidad Marista. Afiliação: Universidad Marista ORCID: https://orcid.org/0000-0002-2696-8023. E-mail: edfra5@ hotmail.com

2 Pasante de la Carrera de Licenciado en Derecho. Afiliação: Universidad Tecnológica de México. E-mail: herreramontes@hotmail.com
} 
of Mexico. For this purpose, we will start from the analysis of various legal systems and criteria of the Judicial Power of the Federation, the cases of Constitutional Courts of other countries, opinions of international organizations as well as doctrinal ones.

Key words: Unconstitutionality action, Constitution of the United States of Mexico, international treaties, general rules, constitutional supremacy, contradiction.

\section{INTRODUCCIÓN}

La acción de inconstitucionalidad (AI o la acción) emerge como un medio de control abstracto de la regularidad de las normas de carácter general confrontado con el texto de la ley fundamental buscando como fin preeminente preservar la unidad normativa del orden jurídico nacional a partir de la supremacía constitucional. ${ }^{3}$

El atributo de medio abstracto obedece a que dentro de este procedimiento de control constitucional no existe contención y las partes no ejercen acción para deducir un derecho propio, por ello el análisis del Tribunal Constitucional se constriñe a contrastar las normas generales impugnadas con el texto de la Constitución Política de los Estados Unidos Mexicanos (CPEUM, Constitución, Constitución Federal, ley fundamental).

El artículo 105 fracción II de la Constitución establece como jurisdicción exclusiva de la Suprema Corte de Justicia de la Nación (SCJN, Corte, alto tribunal, Suprema Corte) conocer de las acciones de inconstitucionalidad que tengan por objeto plantear la posible contradicción entre una norma de carácter general y la propia Constitución.

Estas acciones, continua señalando este numeral, podrán ejercitarse, dentro de los treinta días naturales siguientes a la fecha de publicación de la norma identificando los sujetos facultados constitucionalmente para promoverla (treinta y tres por ciento de los integrantes de la Cámara de Diputados; treinta y tres por ciento de los integrantes de la Cámara de Senadores; el Ejecutivo Federal; el treinta y tres por ciento de los integrantes de los órganos legislativos estatales; los partidos políticos; la Comisión Nacional de los Derechos Humanos o su homólogo en los estados federados; el organismo garante del cumplimiento del derecho de acceso a la información pública y la protección de datos personales en posesión de los sujetos obligados y el Fiscal General de la República).

\footnotetext{
${ }^{3}$ El objeto de esta vía es controlar la regularidad constitucional de las normas generales limitativamente relacionadas en la fracción II del artículo 105 constitucional: tratados internacionales y leyes en sentido estricto, que produzcan un conflicto normativo actual por haber sido ya publicadas y ser de inexorable vigencia; constituye un medio de control abstracto de la constitucionalidad de tales actos, es decir, que no se refiere a la incidencia de la norma a un caso concreto. Ferrer Mac-Gregor, Eduardo, Sánchez Gil, Rubén, 2009, p. 7.
} 
El concepto norma de carácter general referido por este numeral (para efectos de procedibilidad de la acción de inconstitucionalidad) no solo comprende las emanadas materialmente de un procedimiento legislativo (leyes generales, ordinarias, federales o locales) también los tratados internacionales celebrados por el Estado mexicano (al reunir las características de generalidad, abstracción e impersonalidad).

Época: Novena Época, Registro: 194283, Instancia: Pleno, Tipo de Tesis: Jurisprudencia, Fuente: Semanario Judicial de la Federación y su Gaceta, Tomo IX, Abril de 1999, Materia(s): Constitucional, Tesis: P./J. 22/99, Página: 257

\section{ACCIÓN DE INCONSTITUCIONALIDAD. SÓLO PROCEDE CONTRA NORMAS GENERALES QUE TENGAN EL CARÁCTER DE LEYES O DE TRATADOS INTERNACIONALES.}

Del análisis y la interpretación de la fracción II del artículo 105 de la Constitución Política de los Estados Unidos Mexicanos, se advierte que: a) Si las acciones de inconstitucionalidad tienen por objeto plantear la posible contradicción entre una norma de carácter general y la Constitución, entonces sólo son procedentes contra normas de carácter general; b) En el propio precepto se habla sólo de leyes y tratados internacionales entendidos como normas de carácter general. Consecuentemente, las acciones de inconstitucionalidad proceden contra normas de carácter general, pero no contra cualquiera de éstas, sino sólo contra aquellas que tengan el carácter de leyes, o bien, de tratados internacionales. En iguales términos, la Ley Reglamentaria de las Fracciones I y II del Artículo 105 Constitucional, tratándose de acciones de inconstitucionalidad, se refiere únicamente a normas generales, leyes y tratados internacionales; por lo tanto, también debe concluirse que prevé la procedencia de las acciones de inconstitucionalidad exclusivamente en contra de esas normas. La intención del Constituyente Permanente, al establecer las acciones de inconstitucionalidad, fue la de instituir un procedimiento mediante el cual se pudiera confrontar una norma de carácter general con la Constitución y que la sentencia que se dictara tuviera efectos generales, a diferencia de lo que sucede con el juicio de amparo, en el que la sentencia sólo tiene efectos para las partes. No puede aceptarse su procedencia contra normas diversas, ya que en tales casos, por la propia naturaleza del acto combatido, la sentencia no tiene efectos generales, sino relativos. Por ello, de conformidad con lo dispuesto en los artículos 59 y 19, fracción VIII, de la Ley Reglamentaria de las Fracciones I y II del Artículo 105 de la Constitución Política de los Estados Unidos Mexicanos, en relación con el artículo 1o. de la misma ley y con la fracción II del artículo 105 constitucional, las acciones de inconstitucionalidad sólo son procedentes contra normas de carácter general, es decir leyes o tratados, y son improcedentes en contra de actos que no tengan tal carácter.

Los tratados internacionales (TI, tratados, convenciones) atendiendo a su atributo de norma general, pueden ser materia de un planteamiento de contradicción con el texto de la ley fundamental mediante la interposición de una acción de inconstitucionalidad. 


\section{LOS TRATADOS INTERNACIONALES Y LA ACCIÓN DE INCONSTITUCIONALIDAD}

Los tratados internacionales son definidos como un acuerdo internacional celebrado por escrito entre Estados y regido por el derecho internacional. ${ }^{4}$

La incorporación de los tratados internacionales al orden jurídico mexicano obedece al cumplimiento de tres exigencias constitucionales: celebración por el Ejecutivo Federal (art. 89X), aprobación del Senado de la República (art. 76-I) y texto conforme a lo dispuesto en la Constitución (art. 133).

La posición jerárquica de los tratados internacionales dentro de la estructura normativa nacional ha sido fijada por la SCJN en heterogéneos criterios, así, unas veces los ha considerado de igual jerarquía normativa que las leyes federales

Época: Octava Época, Registro: 205596, Instancia: Pleno de la SCJN, Tipo de Tesis: Aislada, Fuente: Gaceta del Semanario Judicial de la Federación, Núm. 60, Diciembre de 1992, Materia(s): Constitucional

Tesis: P. C/92, Página: 27

LEYES FEDERALES Y TRATADOS INTERNACIONALES. TIENEN LA MISMA JERARQUIA NORMATIVA.

De conformidad con el artículo 133 de la Constitución, tanto las leyes que emanen de ella, como los tratados internacionales, celebrados por el ejecutivo Federal, aprobados por el Senado de la República y que estén de acuerdo con la misma, ocupan, ambos, el rango inmediatamente inferior a la Constitución en la jerarquía de las normas en el orden jurídico mexicano. Ahora bien, teniendo la misma jerarquía, el tratado internacional no puede ser criterio para determinar la constitucionalidad de una ley ni viceversa. Por ello, la Ley de las Cámaras de Comercio y de las de Industria no puede ser considerada inconstitucional por contrariar lo dispuesto en un tratado internacional.

Otras de jerarquía normativa superior a las leyes federales:

Época: Novena Época, Registro: 192867, Instancia: Pleno, Tipo de Tesis: Aislada, Fuente: Semanario Judicial de la Federación y su Gaceta, Tomo X, Noviembre de 1999, Materia(s): Constitucional, Tesis: P. LXXVII/99, Página: 46

TRATADOS INTERNACIONALES. SE S UBICAN
JERÁRQUICAMENTE POR ENCIMA DE LAS LEYES FEDERALES Y
EN UN SEGUNDO PLANO RESPECTO DE LA CONSTITUCIÓN
FEDERAL.

Persistentemente en la doctrina se ha formulado la interrogante respecto a la jerarquía de normas en nuestro derecho. Existe unanimidad respecto de que la Constitución Federal es la norma fundamental y que aunque en principio la

\footnotetext{
${ }^{4}$ Artículo 2, numeral 1 inciso a) de la Convención de Viena sobre el Derecho de los Tratados (Convención o Convención de Viena). Esta Convención fue aprobada por el Senado de la República el once de diciembre de mil novecientos ochenta y siete (Diario Oficial de la Federación del once de enero de mil novecientos ochenta y ocho) y ratificada por el Ejecutivo Federal el catorce de enero del mil novecientos ochenta y ocho, siendo depositado ante el Secretario General de la Organización de las Naciones Unidas el diez de marzo del propio año.
} vol.13, nº.02, RiodeJaneiro, 2020.pp.632-651 
expresión "... serán la Ley Suprema de toda la Unión ..." parece indicar que no sólo la Carta Magna es la suprema, la objeción es superada por el hecho de que las leyes deben emanar de la Constitución y ser aprobadas por un órgano constituido, como lo es el Congreso de la Unión y de que los tratados deben estar de acuerdo con la Ley Fundamental, lo que claramente indica que sólo la Constitución es la Ley Suprema. El problema respecto a la jerarquía de las demás normas del sistema, ha encontrado en la jurisprudencia y en la doctrina distintas soluciones, entre las que destacan: supremacía del derecho federal frente al local y misma jerarquía de los dos, en sus variantes lisa y llana, y con la existencia de "leyes constitucionales", y la de que será ley suprema la que sea calificada de constitucional. No obstante, esta Suprema Corte de Justicia considera que los tratados internacionales se encuentran en un segundo plano inmediatamente debajo de la Ley Fundamental y por encima del derecho federal y el local. Esta interpretación del artículo 133 constitucional, deriva de que estos compromisos internacionales son asumidos por el Estado mexicano en su conjunto y comprometen a todas sus autoridades frente a la comunidad internacional; por ello se explica que el Constituyente haya facultado al presidente de la República a suscribir los tratados internacionales en su calidad de jefe de Estado y, de la misma manera, el Senado interviene como representante de la voluntad de las entidades federativas y, por medio de su ratificación, obliga a sus autoridades. Otro aspecto importante para considerar esta jerarquía de los tratados, es la relativa a que en esta materia no existe limitación competencial entre la Federación y las entidades federativas, esto es, no se toma en cuenta la competencia federal o local del contenido del tratado, sino que por mandato expreso del propio artículo 133 el presidente de la República y el Senado pueden obligar al Estado mexicano en cualquier materia, independientemente de que para otros efectos ésta sea competencia de las entidades federativas. Como consecuencia de lo anterior, la interpretación del artículo 133 lleva a considerar en un tercer lugar al derecho federal y al local en una misma jerarquía en virtud de lo dispuesto en el artículo 124 de la Ley Fundamental, el cual ordena que "Las facultades que no están expresamente concedidas por esta Constitución a los funcionarios federales, se entienden reservadas a los Estados.". No se pierde de vista que en su anterior conformación, este Máximo Tribunal había adoptado una posición diversa en la tesis P. C/92, publicada en la Gaceta del Semanario Judicial de la Federación, Número 60, correspondiente a diciembre de 1992, página 27, de rubro: "LEYES FEDERALES Y TRATADOS INTERNACIONALES. TIENEN LA MISMA JERARQUÍA NORMATIVA."; sin embargo, este Tribunal Pleno considera oportuno abandonar tal criterio y asumir el que considera la jerarquía superior de los tratados incluso frente al derecho federal.

$\mathrm{Y}$ en recientes criterios se les ha constituido como parámetros de la regularidad constitucional en el tema de los derechos humanos. ${ }^{5}$

Época: Décima, Registro: 2006224, Instancia: Pleno, Tipo de Tesis: Jurisprudencia, Fuente: Gaceta del Semanario Judicial de la Federación, Libro 5, abril de 2014, Tomo I, Materia(s): Constitucional, Tesis: P./J. 20/2014 (10a.), Página: 202

DERECHOS HUMANOS CONTENIDOS EN LA CONSTITUCIÓN Y EN LOS TRATADOS INTERNACIONALES. CONSTITUYEN EL PARÁMETRO DE CONTROL DE REGULARIDAD CONSTITUCIONAL, PERO CUANDO EN LA CONSTITUCIÓN HAYA UNA RESTRICCIÓN

\footnotetext{
${ }^{5}$ Ver Herrera Pérez, Alberto, 2016.
} 
EXPRESA AL EJERCICIO DE AQUÉLLOS, SE DEBE ESTAR A LO QUE ESTABLECE EL TEXTO CONSTITUCIONAL.

El primer párrafo del artículo 1o. constitucional reconoce un conjunto de derechos humanos cuyas fuentes son la Constitución y los tratados internacionales de los cuales el Estado Mexicano sea parte. De la interpretación literal, sistemática y originalista del contenido de las reformas constitucionales de seis y diez de junio de dos mil once, se desprende que las normas de derechos humanos, independientemente de su fuente, no se relacionan en términos jerárquicos, entendiendo que, derivado de la parte final del primer párrafo del citado artículo 1o., cuando en la Constitución haya una restricción expresa al ejercicio de los derechos humanos, se deberá estar a lo que indica la norma constitucional, ya que el principio que le brinda supremacía comporta el encumbramiento de la Constitución como norma fundamental del orden jurídico mexicano, lo que a su vez implica que el resto de las normas jurídicas deben ser acordes con la misma, tanto en un sentido formal como material, circunstancia que no ha cambiado; lo que sí ha evolucionado a raíz de las reformas constitucionales en comento es la configuración del conjunto de normas jurídicas respecto de las cuales puede predicarse dicha supremacía en el orden jurídico mexicano. Esta transformación se explica por la ampliación del catálogo de derechos humanos previsto dentro de la Constitución Política de los Estados Unidos Mexicanos, el cual evidentemente puede calificarse como parte del conjunto normativo que goza de esta supremacía constitucional. En este sentido, los derechos humanos, en su conjunto, constituyen el parámetro de control de regularidad constitucional, conforme al cual debe analizarse la validez de las normas y actos que forman parte del orden jurídico mexicano. (énfasis añadido).

Advirtamos como el contenido de los tratados internacionales debe subordinarse al texto de la Constitución ${ }^{6}$ situándolos en una posición jerárquica normativa inferior a ésta (principio de supremacía constitucional).

Esta sumisión normativa puede originar supuestos de contradicción en el nivel jerárquico y observancia de los tratados internacionales (sobre todo los relativos a derechos humanos) cuando su espectro tutelar es más amplio al previsto en la Constitución y ésta comprime, limita, o excluye, en razón a esa supremacía, el contenido, alcance y obediencia a los instrumentos jurídicos supranacionales.

De igual manera pueden surgir hipótesis de contradicción entre los tratados internacionales y la CPEUM cuando se presuma la existencia de violaciones por parte de aquellos a derechos humanos o bien a las garantías previstas en la Constitución.

Bajo estas ideas, la posible contradicción entre el texto constitucional y un tratado internacional puede desencadenar la interposición de un medio de control constitucional.

\footnotetext{
${ }^{6}$ Artículo 133. Esta Constitución, las leyes del Congreso de la Unión que emanen de ella y todos los tratados que estén de acuerdo con la misma, celebrados y que se celebren por el Presidente de la República, con aprobación del Senado, serán la Ley Suprema de toda la Unión. Los jueces de cada entidad federativa se arreglarán a dicha Constitución, leyes y tratados, a pesar de las disposiciones en contrario que pueda haber en las Constituciones o leyes de las entidades federativas. (énfasis añadido).
} 


\section{MEDIOS DE IMPUGNACIÓN}

La revisión y análisis de la jurisprudencia de la Suprema Corte de Justicia de la Nación nos arroja una aparente antinomia de criterios respecto del medio de defensa idóneo previsto por la Constitución para conocer la posible contradicción entre ésta y los tratados internacionales (normas de carácter general):

Época: Novena, Registro: 180432, Instancia: Pleno, Jurisprudencia, Fuente: Semanario Judicial de la Federación y su Gaceta, Tomo XX, septiembre de 2004, Materia(s): Constitucional, Tesis: P./J. 84/2004, Página: 1258

TRATADOS INTERNACIONALES. SON NORMAS GENERALES Y, POR TANTO, SON IMPUGNABLES EN CONTROVERSIA CONSTITUCIONAL.

Los tratados internacionales son normas generales, ya que reúnen las características de generalidad, permanencia y abstracción y, además, las materias enunciadas por la fracción X del artículo 89 de la Constitución Política de los Estados Unidos Mexicanos como propias de dichos instrumentos autodeterminación de los pueblos, no intervención, solución pacífica de controversias, etcétera-, sólo pueden tener su expresión creadora y desarrollo lógico a través de normas generales, lo que se corrobora con lo previsto en el artículo 133 constitucional, que expresamente los coloca junto con otras normas, como la Ley Suprema de la Unión, siempre que sean acordes con la misma. En ese sentido, al tener los mencionados instrumentos internacionales la naturaleza de normas u ordenamientos generales, son susceptibles de control constitucional a través de la controversia que establece la fracción I del artículo 105 constitucional, que aunque no incluye de modo explícito entre los actos impugnables a la especie "tratados", sí menciona expresamente como actos sometidos a su control a las "disposiciones generales" que es el género, como se infiere de los incisos h), i), j) y k) de dicha fracción, además de que ese alcance se halla implícito en los demás incisos, donde no se excluyen más actos que los que corresponden a la materia electoral; aunado a que en el penúltimo párrafo de la mencionada fracción I, al señalar los efectos de la sentencia de invalidez se parte del supuesto de que la controversia constitucional procede en contra de disposiciones generales, que comprenden a los tratados.

Criterio en sentido contrario:

Época: Novena, Registro: 194283, Instancia: Pleno, Tipo de Tesis: Jurisprudencia, Fuente: Semanario Judicial de la Federación y su Gaceta, Tomo IX, abril de 1999, Materia(s): Constitucional, Tesis: P./J. 22/99, Página: 257

ACCIÓN DE INCONSTITUCIONALIDAD. SÓLO PROCEDE CONTRA NORMAS GENERALES QUE TENGAN EL CARÁCTER DE LEYES O DE TRATADOS INTERNACIONALES.

Del análisis y la interpretación de la fracción II del artículo 105 de la Constitución Política de los Estados Unidos Mexicanos, se advierte que: a) Si las acciones de inconstitucionalidad tienen por objeto plantear la posible contradicción entre una norma de carácter general y la Constitución, entonces sólo son procedentes contra normas de carácter general; b) En el propio precepto se habla sólo de leyes y tratados internacionales entendidos como normas de carácter general. 
Consecuentemente, las acciones de inconstitucionalidad proceden contra normas de carácter general, pero no contra cualquiera de éstas, sino sólo contra aquellas que tengan el carácter de leyes, o bien, de tratados internacionales. En iguales términos, la Ley Reglamentaria de las Fracciones I y II del Artículo 105 Constitucional, tratándose de acciones de inconstitucionalidad, se refiere únicamente a normas generales, leyes y tratados internacionales; por lo tanto, también debe concluirse que prevé la procedencia de las acciones de inconstitucionalidad exclusivamente en contra de esas normas. La intención del Constituyente Permanente, al establecer las acciones de inconstitucionalidad, fue la de instituir un procedimiento mediante el cual se pudiera confrontar una norma de carácter general con la Constitución y que la sentencia que se dictara tuviera efectos generales, a diferencia de lo que sucede con el juicio de amparo, en el que la sentencia sólo tiene efectos para las partes. No puede aceptarse su procedencia contra normas diversas, ya que en tales casos, por la propia naturaleza del acto combatido, la sentencia no tiene efectos generales, sino relativos. Por ello, de conformidad con lo dispuesto en los artículos 59 y 19, fracción VIII, de la Ley Reglamentaria de las Fracciones I y II del Artículo 105 de la Constitución Política de los Estados Unidos Mexicanos, en relación con el artículo 1o. de la misma ley y con la fracción II del artículo 105 constitucional, las acciones de inconstitucionalidad sólo son procedentes contra normas de carácter general, es decir leyes o tratados, y son improcedentes en contra de actos que no tengan tal carácter.

Analicemos estos aparentes criterios disímiles de nuestro más alto tribunal.

El artículo 105 fracción II constitucional en su inciso b desde su origen (1994) señaló como uno de los sujetos legitimados para interponer la acción de inconstitucionalidad en contra de tratados internacionales celebrados por el Estado mexicano al treinta y tres por ciento de los integrantes del Senado de la República lo que permite inferir que el Constituyente Permanente consideró las convenciones internacionales dentro de los actos impugnables a través de la AI.

La originaria Ley Reglamentaria de las fracciones I y II del artículo 105 de la Constitución Política de los Estados Unidos Mexicanos (LRF-I y II) publicada en el Diario Oficial de la Federación (DOF) el 11 de mayo de 1995, en su artículo 60 señaló:

\footnotetext{
Artículo 60. El plazo para ejercitar la acción de inconstitucionalidad será de treinta días naturales contados a partir del día siguiente a la fecha en que la ley $o$ tratado internacional impugnado sean publicados en el correspondiente medio oficial. Si el último día del plazo fuese inhábil, la demanda podrá presentarse el primer día hábil siguiente.
}

Advirtamos como desde el inicio de la vigencia de esta Ley se reservó la impugnación de los tratados internacionales a la acción de inconstitucionalidad.

En el caso de las tesis jurisprudenciales enunciadas, la aparente contradicción obedece a que en la número P./J.84/2004 el tema materia de la controversia se refirió a un posible 
conflicto competencial entre poderes u órdenes de gobierno con motivo de la aplicación de un tratado internacional que permitió la interposición de una controversia constitucional. ${ }^{7}$

Salvo este caso aislado y sui géneris, el medio de control constitucional idóneo para impugnar la contradicción entre un instrumento jurídico supranacional y la Constitución Federal Mexicana es la acción de inconstitucionalidad.

\section{ESCENARIOS POSIBLES}

La interposición de una acción de inconstitucionalidad por la posible existencia de una contradicción ${ }^{8}$ entre los tratados internacionales y la Constitución puede generar los escenarios siguientes:

\section{Tratados internacionales donde el Estado mexicano sea parte que:}

a) Vulneren un derecho fundamental ${ }^{9}$ reconocido en la Constitución;

b) Vulneren una garantía ${ }^{10}$ establecida en la Constitución;

c) Confieran a un derecho humano un radio de protección superior al otorgado por la Constitución;

d) Concedan a una garantía un perímetro tutelar superior al señalado en la Constitución;

e) Reconozcan un derecho fundamental no previsto en la Constitución, y

f) Otorguen una garantía no prevista en la Constitución.

\section{Tratados vulnerantes de un derecho fundamental}

Instrumentos jurídicos supranacionales cuyas cláusulas o artículos se consideran lesivos al suprimir o restringir derechos humanos reconocidos por la Constitución.

\footnotetext{
${ }^{7}$ Recordemos que la controversia constitucional es una instancia jurisdiccional promovida en única instancia ante la Suprema Corte de Justicia de la Nación cuando se suscitan conflictos competenciales entre poderes o ámbitos de gobierno.

${ }^{8}$ Consideramos contradicción, para efectos de nuestra investigación, no sólo cuando los fines o alcances del instrumento internacional son lesivos o contrarios al texto constitucional sino inclusive en los casos de resultar más favorable el radio de tutela supranacional al establecido en la Constitución.

9 Se consideran fundamentales aquellos derechos humanos reconocidos por la Constitución o un tratado internacional.

${ }^{10}$ Entendiendo por ésta el medio técnico orientado a proteger las disposiciones constitucionales cuando son infringidas, reintegrando el orden jurídico violado.
} 


\section{Tratados vulnerantes de una garantía}

Instrumentos internacionales cuyo contenido limita, restringe o extingue el objeto, alcance o finalidades de una garantía (juicio de amparo, juicio de protección de derechos político-electorales; procedimientos ante comisiones de defensa de los derechos humanos, acción de inconstitucionalidad, controversia constitucional, etc.) establecida en la Constitución. ${ }^{11}$

\section{Tratados que otorgan a un derecho fundamental un radio de protección superior al establecido en la Constitución.}

Instrumentos jurídicos supranacionales contradictorios in bonam partem con el texto constitucional al otorgar una protección superior o de mayor amplitud tutelar al derecho humano reconocido en la norma suprema. ${ }^{12}$

\section{Tratados que confieren a una garantía un perímetro tutelar superior al señalado en la Constitución.}

\footnotetext{
${ }^{11}$ Época: Décima, Registro: 2017890, Instancia: Segunda Sala, Tipo de Tesis: Aislada, Fuente: Gaceta del Semanario Judicial de la Federación, Libro 58, Septiembre de 2018, Tomo I, Materia(s): Constitucional, Tesis: 2a. LXXXVIII/2018 (10a.), Página: 1213

DERECHOS HUMANOS Y GARANTÍAS. SUS DIFERENCIAS.

Conforme al artículo 1o., primer párrafo, de la Constitución Política de los Estados Unidos Mexicanos, todas las personas gozarán de los derechos humanos reconocidos en ella y en los tratados internacionales de los que el Estado Mexicano sea parte, así como de las garantías para su protección. A diferencia de los derechos humanos, en sí mismos considerados, las garantías se erigen como instrumentos o herramientas para su protección y tutela, reforzando su vigencia y salvaguardando su eficacia dentro del sistema normativo. En síntesis, las garantías operan como medidas jurídicas que tienen como finalidad lograr la consecución, vigencia y efectividad de los derechos humanos al tiempo que aseguran la conservación de su carácter ontológico como límites jurídicos infranqueables para la potestad de la autoridad como lo ordena el primer párrafo del artículo 1o. constitucional.

${ }^{12}$ Recordemos el caso del arraigo domiciliario al cual la SCJN en criterio jurisprudencial consideró violatorio de derechos fundamentales al afectar la libertad personal (Época: Novena, Registro: 192829, Instancia: Primera Sala, Tipo de Tesis: Jurisprudencia, Fuente: Semanario Judicial de la Federación y su Gaceta, Tomo X, Noviembre de 1999, Materia(s): Penal, Tesis: 1a./J. 78/99, Página: 55, ARRAIGO DOMICILIARIO, ORDEN DE. AFECTA LA LIBERTAD PERSONAL). Para el año de emisión de este criterio (1999) se encontraban vigentes la Convención Americana sobre Derechos Humanos (Pacto de San José) y el Pacto de Derechos Civiles y Políticos que prohíben la privación de la libertad física y detenciones arbitrarias, no obstante, en fecha 18 de junio de 2008 a través de una reforma se "constitucionaliza" el arraigo domiciliario (art. 16) permitiendo su aplicación para diversos tipos delictivos no obstante encontrarse vigentes estas convenciones internacionales (de obligatorio cumplimiento para nuestro país), este es un claro ejemplo de tratados internacionales que no obstante otorgar mayores alcances tutelares respecto de un derecho humano (libertad personal) son actualmente inaplicables, en este tema, en México por no estar conformes con el texto de la Constitución.
} 
Tratados internacionales contradictorios in bonam partem con el texto de la Constitución al conferir una protección superior o de mayor amplitud a la garantía o garantías previstas en la carta magna. ${ }^{13}$

\section{Tratados que reconocen un derecho fundamental no previsto en la Constitución.}

Instrumentos jurídicos supranacionales contradictorios con el sentido o fines de la Constitución al reconocer un derecho fundamental no establecido en la misma. ${ }^{14}$

\section{Tratados que otorgan una garantía no prevista en la Constitución.}

Instrumentos jurídicos supranacionales contradictorios con el sentido o fines de la Constitución al tutelar una garantía no prevista en el texto constitucional. ${ }^{15}$

En estos últimos cuatro casos la contradicción normativa entre el texto del tratado internacional y la Constitución (antinomia derivada precisamente de la existencia de un más amplio espectro tutelar de los derechos humanos de fuente internacional que el previsto por la CPEUM) permitirían la interposición de una acción de inconstitucionalidad.

\section{EXCURSO}

En principio el sentido de la determinación a dictarse en la acción de inconstitucionalidad, en el caso de contradicciones con el texto o fines ${ }^{16}$ de la ley fundamental, podría decantarse hacia la inaplicabilidad de los tratados internacionales atendiendo al contenido del artículo 133 constitucional, sin embargo, en el caso de los derechos humanos de fuente internacional esta última consideración (contradicción con la Constitución y aplicación preferente de ésta) debe atender al contenido del artículo 1 constitucional ${ }^{17}$ que ordena la

\footnotetext{
13 Como ejemplo podemos mencionar el denominado amparo internacional en materia de derechos humanos (Declaración Americana de los Derechos Humanos, Declaración Universal de los Derechos Humanos, Pacto Internacional de Derechos Civiles y Políticos, y Convención Americana sobre Derechos Humanos) el cual confiere un medio de defensa supranacional más allá de los recursos jurisdiccionales nacionales de carácter doméstico $(v . g r$. el procedimiento ante la Corte Interamericana de Derechos Humanos).

14 V.gr. el derecho a la personalidad jurídica o el derecho al nombre (Convención Americana sobre Derechos Humanos) o bien el derecho al libre desarrollo de la personalidad (Declaración Universal de los Derechos Humanos).

${ }^{15}$ Por ejemplo, el derecho a la indemnización por error judicial (Convención Americana sobre Derechos Humanos).

${ }^{16}$ Principios y valores de naturaleza constitucional.

${ }^{17}$ Artículo 1o. En los Estados Unidos Mexicanos todas las personas gozarán de los derechos humanos reconocidos en esta Constitución y en los tratados internacionales de los que el Estado Mexicano sea parte, así como de las garantías para su protección, cuyo ejercicio no podrá restringirse ni suspenderse, salvo en los casos y bajo las condiciones que esta Constitución establece.
} 
observancia del principio pro homine, esto es, acudir a la norma más amplia o a la interpretación más extensiva cuando se trate de tutelar estos derechos. ${ }^{18}$

Época: Décima Época, Registro: 2005477, Instancia: Tribunales Colegiados de Circuito, Tipo de Tesis: Jurisprudencia, Fuente: Gaceta del Semanario Judicial de la Federación, Libro 3, Febrero de 2014, Tomo III, Materia(s): Constitucional, Común, Tesis: II.3o.P. J/3 (10a.), Página: 2019

\section{PRINCIPIO PRO HOMINE O PRO PERSONA. SI EN UN CASO CONCRETO NO SE ACTUALIZA LA ANTINOMIA DE DOS NORMAS QUE TUTELAN DERECHOS HUMANOS PARA QUE EL JUZGADOR INTERPRETE CUÁL ES LA QUE RESULTA DE MAYOR BENEFICIO PARA LA PERSONA, AQUÉL NO ES EL IDÓNEO PARA RESOLVERLO.}

La Corte Interamericana de Derechos Humanos, al explicar el alcance de este principio, en relación con las restricciones de los derechos humanos, expresó que "entre varias opciones para alcanzar ese objetivo debe escogerse aquella que restrinja en menor escala el derecho protegido". Así, cuando esa regla se manifiesta mediante la preferencia interpretativa extensiva, implica que ante diferentes interpretaciones de un dispositivo legal, debe optarse por aquella que conduzca a una mejor y más amplia protección de los derechos fundamentales, descartando así las que restrinjan o limiten su ejercicio. Bajo este contexto, resulta improcedente que, a la luz del principio pro homine o pro persona, pretendan enfrentarse normas de naturaleza y finalidad distintas, sobre todo, si no tutelan derechos humanos (regulan cuestiones procesales), pues su contenido no conlleva

Las normas relativas a los derechos humanos se interpretarán de conformidad con esta Constitución y con los tratados internacionales de la materia favoreciendo en todo tiempo a las personas la protección más amplia.

${ }^{18}$ El mandato del poder reformador, en el sentido de establecer que la interpretación conforme de las normas relativas a derechos humanos debe realizarse no sólo siguiendo el texto de la Constitución, sino de los tratados internacionales, permite afirmar categóricamente que estos instrumentos jurídicos de fuente internacional se sitúan en el mismo rango jerárquico que nuestra ley fundamental.

Sin embargo, en materia de aplicación de estos tratados, debe atenderse al contenido de los dispuesto por el artículo 133 constitucional, el cual considera ley suprema de la Unión los tratados internacionales que estén de acuerdo con la propia Carta Magna.

Lo anterior hace inferir una obediencia y subordinación de estos instrumentos jurídicos de fuente internacional a la Constitución, inclusive los relativos a derechos humanos, y aún resultando más protectora su aplicación, al no estar de acuerdo con la ley fundamental, podrían estimarse inaplicables. Herrera Pérez. Alberto, 2015. pp- 148 y 149.

Tomando en consideración la existencia de una posible antinomia entre los artículos 1 y 133 constitucionales que impide la aplicación prevalente de los tratados internacionales en materia de derechos humanos sobre el texto constitucional, se considera necesaria la reforma a este último, su actual redacción permite la existencia de una supremacía del texto constitucional respecto de toda la estructura normativa nacional e inclusive convencional esto, en principio, resultaba cierto hasta antes de la reforma constitucional del artículo primero (junio de 2011) la cual elevó al mismo nivel jerárquico a la ley fundamental y los tratados internacionales en materia de interpretación de derechos humanos. Esta reforma encierra una verdadera excepción al principio de supremacía constitucional lo que obligadamente hace necesario una reforma al artículo 133 para armonizar o sincronizar el texto de nuestra ley fundamental y fijar en su exacto sitio dentro del orden jurídico nacional los instrumentos supranacionales en materia de derechos humanos suprimiendo su subordinación al texto constitucional.

Proponemos la siguiente:

Esta Constitución, las leyes del Congreso de la Unión que emanen de ella, los Tratados que estén de acuerdo con la misma y los Tratados relativos a derechos humanos celebrados y que se celebren por el Presidente de la República con aprobación del Senado, serán la Ley Suprema de toda la Unión. Los jueces de cada Estado se arreglarán a dicha Constitución, leyes y tratados, a pesar de las disposiciones en contrario que pueda haber en las Constituciones o leyes de los Estados. 
oposición alguna en materia de derechos fundamentales, de modo que el juzgador pudiera interpretar cuál es la que resulta de mayor beneficio para la persona; de ahí que si entre esas dos normas no se actualiza la antinomia sobre dicha materia, el citado principio no es el idóneo para resolver el caso concreto.

Un tratado internacional ratificado por nuestro país de contenido tutelar extensivo o amplificador de los derechos humanos reconocidos por la Constitución debe alcanzar aplicación prevalente, aun siendo contraria al texto de la ley fundamental, en observancia al principio pro homine. ${ }^{19}$

\section{PROBLEMÁTICA DE LA ACCIÓN DE INCONSTITUCIONALIDAD FRENTE A LOS TRATADOS INTERNACIONALES}

De manera inicial debemos apuntar la ausencia en el orden jurídico mexicano de reglas específicas sobre los elementos que deben contener las sentencias dictadas en la acción de inconstitucionalidad que declaren la inexistencia entre un tratado internacional y el texto de la Constitución.

Debe puntualizarse además que la LRF I y II no prevé un tratamiento específico ni requisitos procesales especiales para la interposición de la AI en contra de tratados internacionales.

Veamos algunos ejemplos: el artículo 61 de la LRF-I y II hace referencia a los elementos que debe contener la demanda a través de la cual se ejercita la acción de inconstitucionalidad estableciendo en su fracción II que deben mencionarse dentro de ésta:

\footnotetext{
${ }^{19}$ Por lo demás, este principio no debe considerarse como de aplicación exclusiva por nuestra Constitución por encontrarse previsto en ésta, el mismo alcanza un rango universal que exige su observancia tanto respecto de normas nacionales cuanto internacionales protectoras de derechos humanos.

“.. el haber acordado rango constitucional a determinadas normas internacionales, merced a la técnica jurídica del bloque de constitucionalidad, ha servido para que las normas legales puedan ser interpretadas no sólo de conformidad con la Constitución, sino a la luz de la legalidad internacional." Ramelli, Alejandro, op. cit. 168.

"El principio pro persona parece haber sido definido por primera vez por el juez Rodolfo E. Piza Escalante en uno de sus votos adjuntos a una decisión de la Corte Interamericana de Derechos Humanos. En dicha ocasión, el juez Piza afirmó que el principio pro persona es [Un] criterio fundamental [que] [...] impone la naturaleza misma de los derechos humanos, la cual obliga a interpretar extensivamente las normas que los consagran o amplían y restrictivamente las que los limitan o restringen. [De esta forma, el principio pro persona] [...] conduce a la conclusión de que [la] exigibilidad inmediata e incondicional [de los derechos humanos] es la regla y su condicionamiento la excepción.” Medellín Urquiaga, Ximena, Principio pro persona, Suprema Corte de Justicia de la Nación, Organización de las Naciones Unidas, Oficina del Alto Comisionado, Comisión de Derechos Humanos del Distrito Federal, p. 17 [en línea 19 de mayo de 2020] https://www.derechoshumanoscdmx.gob.mx/wp-content/uploads/Metodolog\%C3\%ADa-para-la-
} ense\%C3\%B1anza.pdf 
II. Los órganos legislativos y ejecutivo que hubieran emitido y promulgado las normas generales impugnadas.

De acuerdo a la Ley sobre la Celebración de Tratados (DOF 2 de enero de 1992) los tratados internacionales no se emiten ni se promulgan (se aprueban y ratifican), además, un TI no surge de un órgano legislativo o ejecutivo, tiene su origen en el consenso de voluntades o acuerdos de los países o Estados signantes, estas particularidades generan en un primer momento dificultades para dar cumplimiento a los presupuestos procesales exigidos por la ley reglamentaria en estudio.

La fracción III de este numeral indica como requisito el señalamiento de la norma general: “...cuya invalidez se reclame...”, en el caso de un tratado internacional convendría ponderar si la finalidad es declararse su invalidez, considerando que éstos emanan de un consenso internacional donde se refleja una voluntad colectiva supranacional y no puede un Estado motu proprio, sin violar el principio pacta sunt servanda, invalidar sus efectos mediante un procedimiento jurisdiccional doméstico. La Constitución establece la declaración de invalidez de una norma general en el procedimiento de acción de inconstitucionalidad (artículo 105) en tanto para el caso de los tratados internacionales la Convención de Viena prevé la nulidad. ${ }^{20}$

Las figuras jurídicas de invalidez y nulidad tienen connotaciones y alcances jurídicos diferentes, la primera significa una ausencia de validez del acto desde su inicio al no tener las condiciones exigidas por las leyes, la segunda se origina cuando los actos nacen al mundo jurídico por tener las condiciones de existencia pero defectuosas o imperfectas (nulidad absoluta o relativa), en este orden de ideas, en el caso de una acción de inconstitucionalidad interpuesta con motivo de una posible contradicción entre un tratado internacional y la Constitución debe declararse, en su caso, la nulidad (en debida observancia y congruencia con lo dispuesto en la Convención de Viena) y no la invalidez que señala el texto fundamental vigente. ${ }^{21}$

Respecto de las causales de sobreseimiento la LRF-I y II en su artículo 20 fracción $\mathrm{I}^{22}$ establece la improcedencia del desistimiento de la parte actora en la acción de inconstitucionalidad en los casos de normas generales, sin embargo, pensemos en el caso de la

\footnotetext{
${ }^{20}$ Parte V, Sección segunda de la Convención de Viena sobre el Derecho de los Tratados.

${ }^{21} \mathrm{O}$ bien la suspensión o terminación cuando así correspondiera (figuras jurídicas no previstas por el texto constitucional pero sí por la Convención de Viena).

${ }^{22}$ Artículo 20. El sobreseimiento procederá en los casos siguientes:

I. Cuando la parte actora se desista expresamente de la demanda interpuesta en contra de actos, sin que en ningún caso pueda hacerlo tratándose de normas generales.
} 
necesidad imperiosa de un desistimiento por parte del promovente de este medio de control constitucional interpuesto en contra de un tratado supranacional con la finalidad de evitar al Estado mexicano un conflicto internacional, bajo el amparo de la ley en consulta esta acción sería imposible.

Estos ejemplos nos permiten entender que el tratamiento normativo (constitucional y legislativo) conferido a las normas generales (en sentido formal-material) para efecto de la interposición de la acción de inconstitucionalidad no puede aplicarse de igual manera a los tratados internacionales.

Aún más, las leyes procedentes de congresos locales deben obediencia y regularidad al texto constitucional, éste es su génesis y norma rectora por lo que llegado el caso de una disonancia entre este último y la norma general doméstica puede válidamente el Tribunal Constitucional, vía acción de inconstitucionalidad, declarar su invalidez buscando reafirmar la supremacía de la ley fundamental sobre las normas generales que emanan y deben enmarcarse en el perímetro constitucional.

En el caso de los tratados internacionales nacidos de consensos supranacionales la figura de invalidez no tiene un fundamento convencional como forma de darlos por terminados, por lo tanto precariamente puede declararse una invalidez bajo argumentos emanados o previstos en la Constitución local, no olvidemos el contenido del artículo 27 de la Convención de Viena que establece: "Una parte no podrá invocar las disposiciones de su derecho interno ${ }^{23}$ como justificación del incumplimiento de un tratado".

Resulta ilustrativa sobre este punto la sentencia dictada por la Corte Interamericana de Derechos Humanos en el caso Almonacid Arellano y otros Vs. Chile ${ }^{24}$ la cual en su considerando 125 señaló:

125. En esta misma línea de ideas, esta Corte ha establecido que "[s]egún el derecho internacional las obligaciones que éste impone deben ser cumplidas de buena fe y no puede invocarse para su incumplimiento el derecho interno. Esta regla ha sido codificada en el artículo 27 de la Convención de Viena sobre el Derecho de los Tratados de 1969.

Recordemos: una norma imperativa de derecho internacional es aceptada y reconocida por la comunidad internacional de Estados en su conjunto, no admite acuerdo en contrario y sólo puede ser modificada por una norma ulterior de derecho internacional general que tenga el mismo carácter. ${ }^{25}$

\footnotetext{
${ }^{23}$ Desde luego que dentro del concepto derecho interno queda incluida la Constitución.

24 http://www.corteidh.or.cr/docs/casos/articulos/seriec_154_esp.pdf [en línea 28 de mayo de 2020]

${ }^{25}$ Artículo 53 de la Convención de Viena sobre el Derecho de los Tratados.
} 
La Convención de Viena establece en su Parte V la nulidad, terminación y suspensión de los tratados internacionales, ${ }^{26}$ y es precisamente a esta normatividad que deben sujetarse los Estados firmantes de la Convención para modificar o reformar su vigencia u observancia.

En esta lógica, en rigor técnico y en observancia a este instrumento internacional convencional obligatorio para el Estado mexicano el sentido de la sentencia del Tribunal Constitucional en el procedimiento derivado de la acción de inconstitucionalidad donde se declare una contradicción entre la Constitución y el tratado internacional debe ser su nulidad, terminación o suspensión, estableciéndose en el propio cuerpo de la determinación judicial el procedimiento para su cumplimentación por parte de los otros dos poderes constituidos: Ejecutivo y Legislativo (Cámara de Senadores).

En otras palabras, ante la inexistencia de un procedimiento legalmente establecido que norme el contenido de la resolución dictada en la AI enderezada en contra de un tratado internacional que se considere contradictorio con la Constitución, el único camino legal pulcro que debe seguir la SCJN es dictar su sentencia cumpliendo con el contenido previsto para este efecto por la Convención de Viena y seguir el procedimiento establecido para declarar la nulidad del tratado (que no la invalidez).

Desde luego es deseable una reforma a efecto de precisar en el texto constitucional el contenido y alcance de las sentencias de la SCJN dictadas en la acción de inconstitucionalidad enderezada en contra de tratados internacionales a fin de proporcionar seguridad jurídica y legalidad a sus resoluciones en este tema.

Por nuestra parte proponemos una adición al párrafo final del artículo 105 constitucional fracción II con la redacción siguiente:

Artículo 105. ...

II.

Las resoluciones de la Suprema Corte de Justicia sólo podrán declarar la invalidez de las normas impugnadas, siempre que fueren aprobadas por una mayoría de cuando menos ocho votos. En el caso de los tratados internacionales celebrados por el Estado Mexicano será requerido el mismo número de votos para declarar la contradicción del tratado y esta Constitución. En este último supuesto la sentencia que se dicte establecerá los medios o acciones necesarias para hacer cesar sus efectos dentro del territorio nacional de conformidad a lo previsto en los tratados o convenciones en los que el Estado mexicanos sea parte.

\footnotetext{
${ }^{26}$ Normatividad mínima que ciertamente no aporta gran detalle sobre el procedimiento a seguir para estos casos, lo que lleva a considerar la necesidad de desarrollar un procedimiento constitucional-legal sobre este tema.
} vol.13, $n^{\circ} .02$, Riode Janeiro, 2020.pp.632-651 
La parte más compleja de transitar respecto de la declaración de contradicción entre la Constitución y un tratado internacional se origina en razón a que prima facie existe una convergencia de poderes: Ejecutivo Federal y Senado de la República (Poder Legislativo ${ }^{27}$ ) para atribuirle vida jurídica a este último (que goza de una presunción de constitucionalidad, considerando el procedimiento seguido para su aprobación ${ }^{28}$ ).

Bajo estas condiciones y atendiendo a que en el tema de los tratados internacionales por disposición constitucional convergen dos poderes de la Unión (en debida observancia al principio de división de poderes), se recomendaría la creación legal de un órgano administrativo-legislativo conformado por el Ejecutivo Federal y el Senado de la República el cual, en sede administrativo-legislativa y derivado de facultades legales expresas instrumente la ejecución de la sentencia declaratoria de contradicción con la finalidad de lograr su efectivo cumplimiento y alcanzar una armónica instrumentación con el texto de los tratados internacionales suscritos por el Estado mexicano.

Debe considerarse asimismo como una opción altamente recomendable establecer dentro de la ley fundamental un control previo de constitucionalidad de los tratados internacionales dotando de facultades para este efecto al Tribunal Constitucional ${ }^{29}$ como se ha adoptado en otros países. ${ }^{30}$

\footnotetext{
${ }^{27}$ Facultad constitucional exclusiva prevista para este cuerpo colegiado por el artículo 76 fracción I párrafo segundo de la CPEUM.

${ }^{28}$ Época: Novena, Registro: 171889, Instancia: Segunda Sala, Tipo de Tesis: Aislada, Fuente: Semanario Judicial de la Federación y su Gaceta, Tomo XXVI, Julio de 2007, Materia: Constitucional, Tesis: 2a. LXXXIV/2007, Página: 384 TRATADOS INTERNACIONALES. DEBEN PRESUMIRSE APEGADOS AL TEXTO CONSTITUCIONAL HASTA EN TANTO SE DEMUESTRE SU INCONSTITUCIONALIDAD EN LA VÍA PROCEDENTE.

El artículo 128 de la Constitución Política de los Estados Unidos Mexicanos establece la obligación de todo servidor público de protestar guardar la Constitución y las leyes que de ella emanen; obligación que recae, en el caso de los tratados internacionales, entre otros, en el Presidente y en los miembros del Senado de la República, por lo que los actos provenientes de dichos servidores se presumen constitucionales hasta en tanto se pruebe su inconstitucionalidad ante los Tribunales de la Federación o su ilegalidad ante los Tribunales Contenciosos Administrativos. Así, basta que un tratado internacional lo firme el Ejecutivo, por sí o por conducto de plenipotenciario facultado, lo apruebe el Senado y se publique en el Diario Oficial de la Federación, para presumir que es acorde con la Constitución Federal, en el entendido de que esta presunción legal subsistirá hasta en tanto se declare la inconstitucionalidad o ilegalidad correspondiente por el órgano competente y en vía idónea. Amparo en revisión 120/2002. Mc Cain México, S.A. de C.V. 30 de mayo de 2007. Cinco votos. Ponente: Sergio Salvador Aguirre Anguiano. Secretaria: Andrea Zambrana Castañeda.

${ }^{29}$ Sin embargo, ciertos viejos escrúpulos soberanos (no sólo del Poder Judicial de la Federación sino inclusive del Congreso de la Unión) impiden la instrumentación de este tipo de procedimiento de control previo y más aún, imposible pensar en una consideración relativa a una jerarquía normativa superior de los tratados internacionales sobre el texto hierático de la Constitución (ni aún en el caso de aquellos referidos a temas de derechos humanos con mayores espectros tutelares hacia la persona).

${ }^{30}$ Francia, Italia, Portugal o España. En el mismo sentido Brage Camazano, Jorge, 2004, p. 2.
} 


\section{FUTURO DE LA ACCIÓN DE INCONSTITUCIONALIDAD Y LOS TRATADOS INTERNACIONALES.}

La ausencia de un procedimiento constitucional y legal respecto de los instrumentos jurídicos internacionales revisados en sede judicial donde se declare su contradicción ${ }^{31}$ con el texto de la Constitución Política de los Estados Unidos Mexicanos hace inaplazable su regulación con la finalidad de evitar al Estado mexicano en un futuro próximo serios problemas de responsabilidad en el plano internacional.

En las reformas constitucionales y legales que sugerimos, será necesario incluir, entre otros aspectos, los siguientes:

a) Especificar las facultades constitucionales de la SCJN respecto de la acción de inconstitucionalidad y los tratados internacionales. ${ }^{32}$

b) Establecer a nivel constitucional los alcances (temporales, materiales y espaciales) de la sentencia dictada por la SCJN en la acción de inconstitucionalidad con motivo de una declaratoria de contradicción entre un tratado internacional y la Constitución. ${ }^{33}$

c) Creación de un apartado específico en la LRF-I y II relativo a la acción de inconstitucionalidad y los tratados internacionales.

d) Establecer en la Constitución y posteriormente con mayor amplitud en una ley secundaria la intervención de los poderes Ejecutivo y Legislativo en la cumplimentación de la sentencia declarativa de contradicción entre un tratado internacional y la Constitución.

e) Adecuación normativa de diversos artículos constitucionales con la finalidad de armonizar el tratamiento de los tratados internacionales específicamente los relativos a derechos humanos.

\section{CONCLUSIONES}

\footnotetext{
${ }^{31}$ La cual comprende, como ya sostuvimos, no solo el caso de las normas generales lesivas al texto constitucional sino inclusive las que amplían u otorgan mayores o preferentes aspectos tutelares a los contenidos en la ley fundamental.

${ }^{32}$ Sin considerarlos dentro del concepto normas de carácter general como confusamente se encuentra redactado en la actualidad. Se propone, de nuestra parte, una nueva redacción para la fracción II del artículo 105 constitucional: Artículo 105. La Suprema Corte de Justicia de la Nación conocerá, en los términos que señale la ley reglamentaria, de los asuntos siguientes:

II. De las acciones de inconstitucionalidad que tengan por objeto plantear la posible contradicción entre esta Constitución y una norma de carácter general o un tratado internacional.

${ }^{33}$ Retomando la normatividad internacional sobre el tema.
} 
PRIMERA. No existe dentro del orden jurídico constitucional mexicano normatividad relativa al contenido que deben observar las sentencias dictadas en la acción de inconstitucionalidad en el caso de contradicción entre un tratado internacional y la CPEUM.

SEGUNDA. La acción de inconstitucionalidad se constituye como el medio de control constitucional idóneo para plantear la posible contradicción entre un tratado internacional y la Constitución Federal.

TERCERA. La contradicción del tratado internacional con el texto de la Constitución puede provenir no sólo por la inclusión de artículos o cláusulas de manifiesta violación a los derechos humanos reconocidos constitucionalmente sino inclusive por contener un espectro tutelar más amplio que el previsto por la propia Constitución Federal.

CUARTA. En el caso de los derechos humanos debe el tratado alcanzar una aplicación prevalente al propio texto constitucional en el supuesto de ser más amplio o superior su espectro tutelar en debida observancia al principio pro homine.

QUINTA. Es necesario legislar (inclusive a nivel constitucional) sobre los efectos o consecuencias de las resoluciones dictadas por la Suprema Corte de Justicia de la Nación en las acciones de inconstitucionalidad, en los casos de una posible contradicción entre un tratado internacional y el texto de la Constitución Política de los Estados Unidos Mexicanos.

SEXTA. Es impostergable la reforma a la Ley Reglamentaria de las Fracciones I y II del artículo 105 de la Constitución Política de los Estados Unidos Mexicanos, a fin de crear apartados y consideraciones procesales especiales para la interposición de la acción de inconstitucionalidad en el caso de los tratados internacionales.

SÉTIMA. Para efecto de sincronía normativa debe reformarse el contenido del artículo 133 constitucional en el tema relativo a los tratados internacionales en materia de derechos humanos armonizando el texto del artículo primero de la Constitución en esta materia. En este mismo orden de ideas es necesario modificar el artículo 105 de la norma fundamental para fijar los efectos de la declaratoria de contradicción entre ésta y una convención.

OCTAVA. Debe valorarse conceder facultades a la Suprema Corte de Justicia de la Nación en materia de control previo de constitucionalidad de los tratados internacionales atendiendo a su calidad de Tribunal Constitucional.

NOVENA. Es aconsejable la creación legal de un órgano administrativo-legislativo que instrumente la ejecución de la resolución declaratoria de contradicción entre un tratado internacional y la Constitución mexicana. 


\section{REFERENCIAS BIBLIOGRÁFICAS}

Brage Camazano, Jorge, Universidad Nacional Autónoma de México, Instituto de Investigaciones Jurídicas, La acción abstracta de inconstitucionalidad México 2004.

Convención de Viena sobre el Derecho de los Tratados.

Corte Interamericana de Derechos Humanos. Jurisprudencia.

Diario Oficial de la Federación.

Ferrer Mac-Gregor, Eduardo, Sánchez Gil, Rubén, Efectos y contenidos de las sentencias en acción de inconstitucionalidad, Universidad Nacional Autónoma de México, Instituto de Investigaciones Jurídicas, México, 2009.

Herrera Pérez, Alberto, El control de convencionalidad en materia de Derechos humanos y la regularidad constitucional", en Cuestiones Constitucionales, Revista Mexicana de Derecho Constitucional, Universidad Nacional Autónoma de México, Instituto de Investigaciones Jurídicas, Semestre julio-diciembre 2016. Número 35.

Herrera Pérez, Alberto: "Correlación jerárquica normativa de los tratados internacionales en materia de derechos humanos y la constitución federal mexicana", en Revista El Tribunal Superior de Justicia del Distrito Federal, año VIII, número 22, diciembre 2015.

Ley sobre la Celebración de Tratados.

Ley Reglamentaria de las Fracciones I y II del artículo 105 de la Constitución Política de los Estados Unidos Mexicanos.

Suprema Corte de Justicia de la Nación, Semanario Judicial de la Federación.

Trabalho recebido em 10 de março de 2019

Aceito em 05 de junho de 2020 